\title{
Predicting Manpower Demand in Jiangsu Province of China
}

\author{
Wanli Zhang ${ }^{1, a}$ \\ ${ }^{1}$ Business School of Hohai University, China \\ agorgeous891@live.com
}

Keywords: Predicting; distributed lag model; Manpower demand; Labor multiplier approach

\begin{abstract}
Manpower predicting is a strategic managerial practice that construction organizations should carry out to ensure appropriate number of workforces. To date, many studies have predicted the manpower demand of construction industry in China using methods like gray model and labor productivity model. This paper, however,first develops a mathematical model, combining distributed lag model with labor multiplier approach to improve the accuracy of manpower demand forecast in Jiangsu Province of China. Deriving data from National Bureau of Statistics of China and some project managers, the manpower predicting model can be used as a managerial tool to forecast future labor demand so that optimal number of workforces can be reached.
\end{abstract}

\section{Introduction}

The construction industry is a labor-intensive industry and it plays an important role in economic growth of developing countries such as China. With sustained development of construction industry, it requires larger numbers of workforce to meet the need. However, since the beginning of 2012 the whole nation faces shortage of workforce, the appearance of construction industry labor shortage deteriorates future development of construction industry. Therefore, ensuring the number of workforce guarantees the development of whole construction industry. Forecasting manpower can be an effective practice for governments and business organizations to ensure organizations having the proper personnel. Also, a well-fitted manpower forecasting plan can be used to reflect the changing demand of construction labor market ${ }^{[1]}$.

In order to solve the problem of précising forecasting manpower demand, a plethora of models have been presented ${ }^{[2-4]}$. These models range from simple to mathematically complicate. However, the models developed contain many explanatory variables such as construction added-value and labor productivity which can't be accurately predicted. According to previous researches, this paper explores linkage between construction output and GDP, and its accuracy is not dependent on a variety of variables.

\section{Research Approach}

Labor Multiplier Approach. The multiplier approach makes an assumption that there is a relationship between construction output and manpower demand per construction unit. It is also assumed that the demand for manpower per unit of the construction output remains constant in a short term. If the multiplier is assigned to a specific work trade, then the manpower demand can be calculated.

The data paper needed can be obtained by the site of National Bureau of Statistics of China and private contractors. The multiplier of each trade can be determined by the following equation:

$$
M_{j}^{i}=D_{j}^{i} / C_{j}^{i} .
$$

Where, $\mathrm{M}_{i}^{j}=$ labor multiplier of trade $i$ of the specific project type $j ; \mathrm{D}_{j}^{i}=$ labor deployment(man-days) of trade $i$ of the specific projected type $j ; \mathrm{C}_{j}^{i}=$ project expenditure of the specific project type $j$.

The manpower demand of the construction project is expressed as 


$$
D_{j}^{i}=E_{j} * M_{j}^{i} \cdot(2)
$$

Where, $E_{j}=$ expenditure(RMB 100 million yuan) of project $j$; and $D_{j}^{i}=$ labor demand(unit: man-days)of trade $i$ for a selected $j$ project.

Distributed lag model. Unlike financial assets investment, construction projects are characterized by time elapse between the decision to start a project and the completion of the whole construction. As regarding to such characteristic, distributed lag model is used in forecasting of manpower. The simplest form of a distributed lag model can be expressed as

$$
Y_{t}=\alpha+\beta_{0} X_{t}+\beta_{t-1} X_{t-1}+\cdots+\beta_{q} X_{t-q}+e(3)
$$

Where, $Y_{t}=$ dependent variable at time $t ; X_{t}=$ explanatory variable at time $t ; q=$ lagged order; $e=$ error.

Unlike the traditional distributed lag model, the relationships between $Y$ and $X$ are tested separately. $R$-squared value is used to test the strength of the relationship between yearly change in construction output, $\Delta C O_{t, q}$ and yearly change of the GDP with lag year $q, \Delta G D P_{t-q}$.

The relationship between $\Delta C O_{t, q}$ and $\Delta G D P_{t-q}$ can be determined by following equation $\Delta C O_{t, q}=\alpha+\beta_{0} \Delta \mathrm{GDP}_{t-q}+\beta_{1} \Delta \mathrm{GDP}_{t-q}^{2}+\cdots+\beta_{n} \Delta \mathrm{GDP}_{t-q}^{n+1}+e(4)$

\section{Model formulation and data analysis}

Forecasting future GDP in Jiangsu Province. In order to predict the manpower in Jiangsu Province, the first step is to estimate the forthcoming economic condition of Jiangsu Province. By making references of GDP yearly percentage changed and rebuilding different future scenarios, the prediction of GDP can be attained. Fig 1 and Fig 2 are forecasting patterns under different hypothesis.

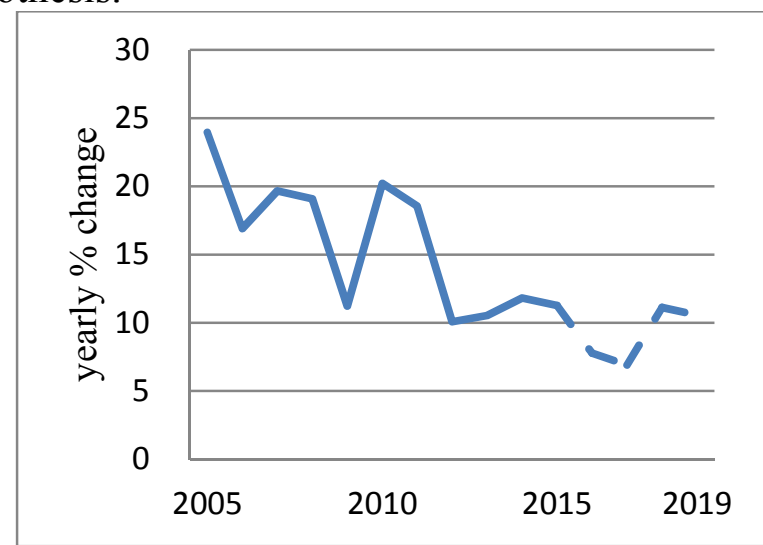

Fig. 1. Low growth of GDP prediction

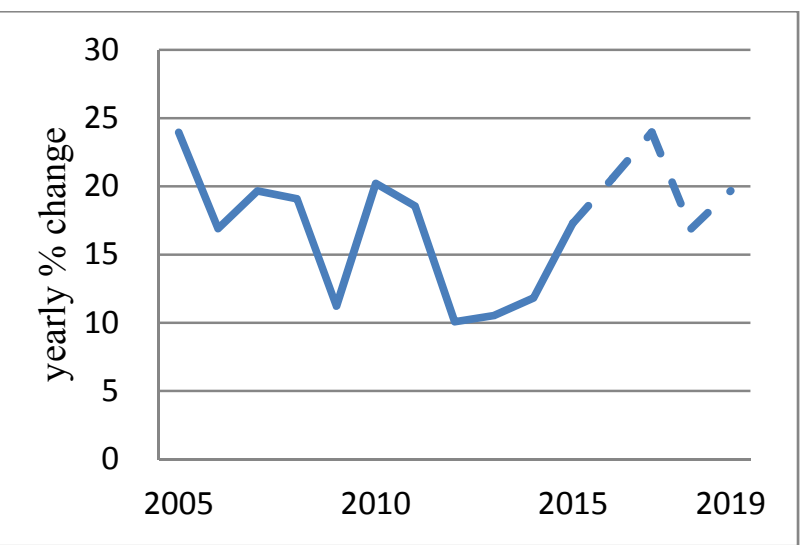

Fig.2. High growth of GDP prediction

Model linking GDP with construction output. The relationship between yearly GDP\% change and yearly construction output \% change can be viewed as following scatter plot.

In table 1, the data is derived from National Bureau of Statistics of China (Jiangsu Province 1994-2014) and the result of regression analysis is represented as Table 1 . The $R^{2}$ value provides a criterion of how well the quadratic regression line fits the data. The significance $F$ is used to test whether $R^{2}$ differs significantly. 


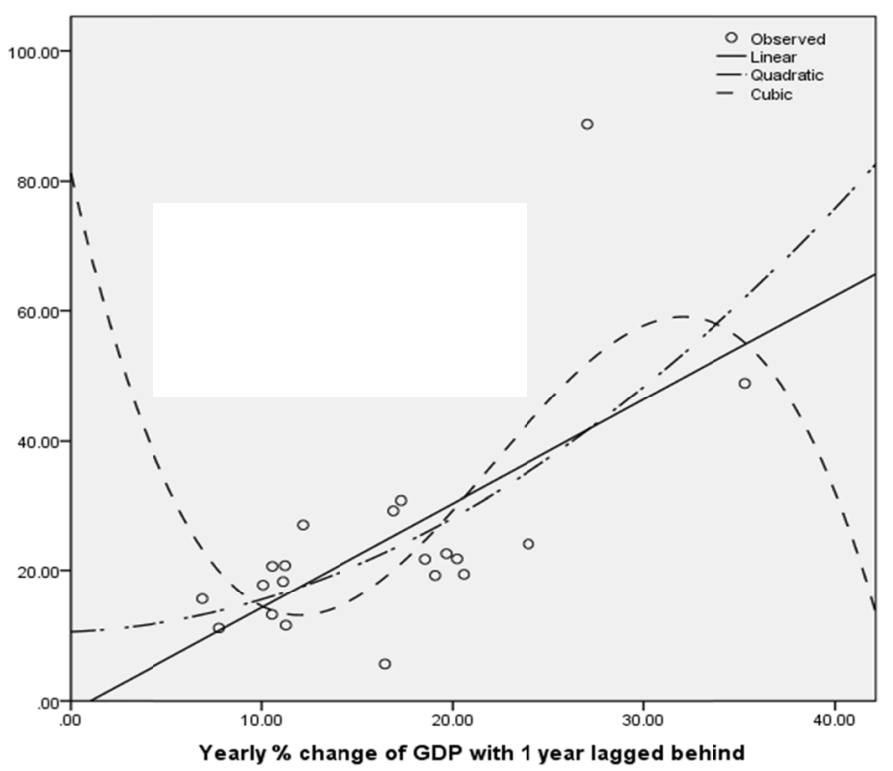

Fig. 3. Scatter plot of yearly $\%$ change of construction output and GDP

From zero. If the significance is larger than 0.05 , it means that $R^{2}$ is near zero and there are no direct relationships between variables of dependence and independence. When the Significance $F$ is not salient, lagged year 4 will not be taken into consideration in the model that developed. The relationship between $\triangle C O_{t, q}$ and $\triangle G D P_{t-q}$ with lagged year 1,2 and 3 are significant.

Table 1. Relationship between GDP with lagged year and Construction Output

\begin{tabular}{|c|c|c|c|c|c|}
\hline Lagged year $q$ & $R^{2}$ & $\alpha$ & $\beta_{0}$ & $\beta_{1}$ & Significance $F$ \\
\hline 1 & 0.436 & 10.609 & 0.121 & 0.038 & 0.008 \\
\hline 2 & 0.673 & 49.221 & -4.478 & 0.149 & 0.000 \\
\hline 3 & 0.342 & 17.160 & 0.729 & -0.03 & 0.043 \\
\hline 4 & 0.349 & 24.211 & -0.015 & -0.011 & 0.051 \\
\hline
\end{tabular}

The results presented in Table 1 are contained in the model that the change of construction output is the function of change of GDP which is shown as

$\Delta F C O_{t}=k\left(0.436 \Delta C O_{t, 1}+0.637 \Delta C O_{t, 2}+0.342 \Delta C O_{t, 3}\right)(5)$

Then forecast of construction output at yeart, $\mathrm{FCO}_{t}$ can be determined by the following equation

$$
F C O_{t}=C O_{t-1} *\left(100+\Delta F C O_{t}\right) / 100^{(6)}
$$

In order to examine whether the proposed model conform to the trend of the percentage change of construction output, the historical statistics are taken to test the validity of the model. The year 2005 is selected as the base. Then the trend is simulated by the proposed model.

Forecast Manpower Demand. (1)Type of trade selected. To determine the number of workers, specific information is obtained from some famous subcontractors. The most common trades are identified in Table 2. Also, the information of project expenditures is required

Table 2. Common Trades

\begin{tabular}{|c|c|}
\hline & Trade $i$ \\
\hline Electrician & Concretor \\
\hline Electric welder & Bricklayer \\
\hline Steel bender & Plasterer \\
\hline Machine operator & Scaffolder \\
\hline Carpenter & General worker \\
\hline
\end{tabular}

1) Process of predicting manpower demand. Using the data from 15 studied construction projects, since projects surveyed are all started in 2014, the project expenditure has no inflation problems. 
Then labor multiplier can be expressed as

$$
L M_{i}=\frac{D_{i}}{C}(7)
$$

Where, $L M_{i}=$ labor multiplier of trade $i$ of a certain project; $D_{i}=$ labor deployment (unit: man-day); $C=$ project expenditure of a project(unit: RMB 100million). The workload (unit: man-days) by applying labor multiplier can be shown as

$$
P W_{t, i}=\sum_{p=1}^{k}\left(F C O_{t} * \gamma_{p}\right) * L M_{i, \gamma_{p}}(8)
$$

Where, $P W_{t, i}=$ predict workload of the trade $i$ (unit: man-days) at yeart:; $F C O_{t}=$ forecast construction output at year $t ; \gamma_{p}=$ percentage of construction project type; $L M_{i, \gamma_{p}}=$ labor multiplier for the trade $i$, at type, $p$ of the construction project.

By taking the working days per year into consideration, the demand for each trade can be derived. The equation is expressed as

$M D_{t, i}=P W_{t, i} / W(9)$

Where, $M D_{t, i}=$ forecast manpower demand for the trade $i$ at year $t$; W=number of working days each year.

2)Measuring the validity of the model established. To illustrate how the proposed model can be used in reality, the historical data is required to testify whether the model can estimate the total number of workforce on construction industry correctly. The documented and predicted numbers of manpower are compared in the Table 3.

Table 3. Manpower number from 2012-2014(unit: 10 thousand people)

\begin{tabular}{|c|c|c|c|}
\hline Year & 2012 & 2013 & 2014 \\
\hline Documented number & 739.34 & 763.48 & 846 \\
\hline Forecasting number & 623.38 & 734.66 & 832.13 \\
\hline
\end{tabular}

3)Projection on workforce of construction industry. So as to forecast the manpower of construction industry, the two economic conditions are used for projection. The former is the forecast construction output (FCO) based on low growth GDP pattern and the latter is the forecast construction output based on high growth GDP pattern. The simulation of future change of construction output are shown in Fig. 4 and Fig. 5.
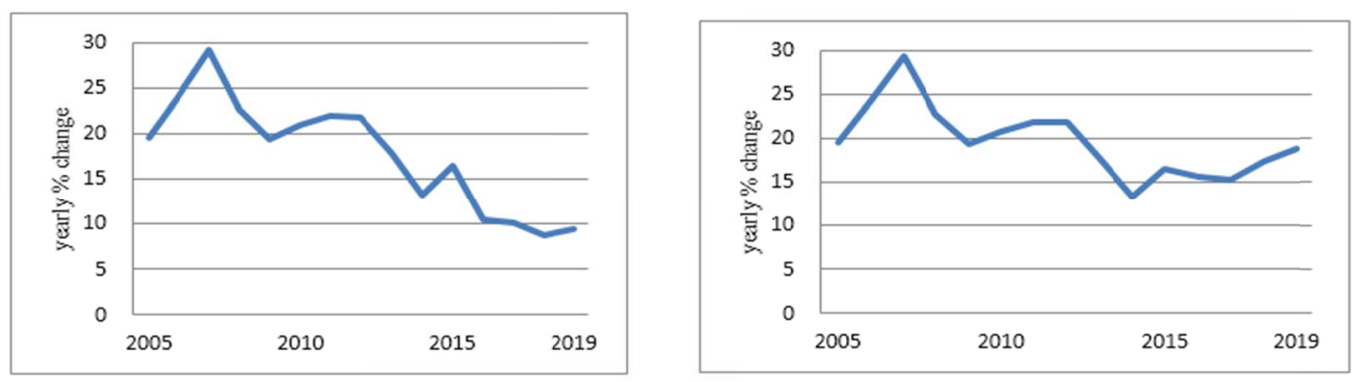

Fig.4. FCO based on low GDP growthFig.5. FCO based on high GDP growth

No raw data on the ratio of construction types presented for publications. The ratio of construction project types is measured by the proportion of certain nominal value to the total construction output of Jiangsu Province. Using Eq.8, 9 and all the data collected, the workforce can be estimated. Table 4 is the results of manpower projection according to two conditions.

Table 4. The results of manpower predicting(unit: 10 thousand people)

\begin{tabular}{|c|c|c|c|c|c|}
\hline Year & 2015 & 2016 & 2017 & 2018 & 2019 \\
\hline FCO(low growth) & 968.93 & 1070.44 & 1178.88 & 1281.12 & 1402.30 \\
\hline $\begin{array}{c}\text { FCO(high } \\
\text { growth) }\end{array}$ & 968.96 & 1121.23 & 1291.60 & 1515.63 & 1802.35 \\
\hline
\end{tabular}

The effect of economic condition is showed in Fig.7. Under low GDP growth condition, the number of construction workers is increasing approximately 1 million every year from 968.93 in 